\title{
Information literacy in the new curriculum
}

\author{
Michiel Moll ${ }^{1}$ \\ Cape Peninsula University of Technology \\ mollm@cput.ac.za
}

Received 20 October 2008

Accepted 14 January 2009

\begin{abstract}
South Africa has undergone a decade of curricular change that has evoked much debate, study and even condemnation. New terminology has entered the public domain. However this huge curriculum revolution had a curious passenger: Information Literacy. Prior to the release of Curriculum 2005, a bold new curriculum for Information Literacy was introduced for use in schools. With the advent of Curriculum 2005, with its totally new paradigm, one would have expected that the Information Literacy curriculum would have disappeared. However, in a somewhat surprising move, it appeared within the curriculum for the new 'Learning Area': Languages, Literacy and Communication. Within this learning area it was found, intact, as one of the four Specific Outcomes, which were seen as the subdivisions of the subject. In the revision of the curriculum called the National Curriculum Statement this changed. This paper studies the position of Information Literacy within this curriculum, within each of the Learning Areas. It also outlines a practical exercise with education students to pinpoint their understanding and recommends actions for the better implementation of information literacy in schools.
\end{abstract}

Keywords: Information Literacy; curriculum; education - South Africa; school libraries

\section{Introduction}

The school curriculum in South Africa has undergone major changes. At the same time, international emphasis on the importance of Information Literacy has found reflection locally in many calls for the development of school libraries (e.g. Arnold 2002: 178), but actual implementation has remained a problem. This is also reflected in initial teacher training which has moved Information Literacy to a skill of teachers, rather than an essential part of the curriculum they have to teach. This paper first looks briefly at the changes in national curricula in South Africa, and then at the current curriculum, with emphasis on the place of Information Literacy concepts within the curriculum as a whole, and then within each Learning Area. An intervention with education students is then described: an attempt was made to guage their understanding of the role of Information Literacy. Finally, a few recommendations are made with regard to how this reflects on schools and school libraries.

\section{Background}

The first document on the position of information skills in the curriculum appeared in 1994 as the "Core Teaching Programme for Information skills" (Moll 1999). In this document the process model of information skills was adopted and schools were expected to replace the existing "Media Guidance" with this new curriculum. However, in 1997 the Heads of Education Departments National Curriculum Committee recommended the Draft Revised National Curriculum Statement for Grades R-9 for Ministerial Approval. This was then published in terms of Government Notice 1445 in October 1997 (South Africa. Department of Education 2002g:5), with the Assessment policy being introduced in December 1998, although the curriculum had already been introduced into schools as from January 1998.

After the first two years of implementation, the Department appointed a review committee to look at, inter alia, the structure and design of the curriculum. This committee presented its report in May 2000, which led to the appointment of a team to revise the National Curriculum Statement. This process culminated in the introduction of the Revised National Curriculum Statement (RNCS) (now known as the National Curriculum Statement) in 2004 (South Africa. Department of Education 2002g:6).

\section{Main elements of the Curriculum 2000 and the RNCS}

The Revised National Curriculum Statement is thus a revision of the original Curriculum 2005 and is not seen as a new curriculum. There are obviously many elements that remain the same, and are based on the curriculum tools developed by the National Department of Education:

- Critical Cross-Field Outcomes (later known as critical and developmental outcomes)

- Specific Outcomes

- Range Statements

I. . Michiel Moll is a Senior Librarian for Professional Information Services at the Cape Peninsula University of Technology 
- Assessment Criteria

- Performance Indicators

- Notional Time and Flexi-time

- Continuous assessment, recording and reporting

- Phase organisers

- Programme organisers

- Expected levels of performance

- Learning programmes (South Africa. Department of Education 2002g:5).

However, there are essential differences in various areas, which we shall look at later.

There are two main training bands, known as General Education and Training Band and the Further Education and Training (FET) Band. The first is the responsibility of schools and was envisioned as ending in a General Education and Training Certificate (South Africa. Department of Education. 2002g:3); it is the subject of both the original Curriculum 2005 and the RNCS. Separate curricula have been devised for the Further Education and Training Band which is also seen as the province of FET colleges as well as schools. This paper deals with the curriculum of the General Education and Training Band, often referred to in the documents as Grades R-9 (schools) (South Africa. Department of Education 2002g).

There are eight Learning Areas in the National Curriculum Statement. They are:

- Languages

- Mathematics

- Natural Sciences

- Technology

- Social Sciences

- Arts and Culture

- Life Orientation

- Economic and Management Sciences

Within each of these we find assessment standards and learning outcomes which are "designed down from the critical and developmental outcomes" (South Africa. Department of Education 2002g: I I).

These learning outcomes and assessment standards are divided into requirements and expectations in three phases: Foundation Phase (Grades R-3), Intermediate Phase (Grades 4-6) and Senior Phase (Grades 7 -9). The learning outcome will describe what the learner should know, be able to do and to demonstrate at the end of each appropriate period; the assessment standard describes the extent to which the learner should be able to do this, and in what way they can demonstrate this. This means that: "the learning outcomes can and will, in most cases, remain the same from grade to grade, while assessment standards change from grade to grade" (South Africa. Department of Education 2002g: 14).

\section{Critical and developmental outcomes}

With all subject outcomes being derived from these, it is clear that they form the basis of the new curriculum. The critical outcomes are phrased in the type of abilities learners are expected to be able to demonstrate, so that learners should be able to:

- Identify and solve problems and make decisions using critical and creative thinking

- Work effectively with others as members of a team, group, organisation and community

- Organise and manage themselves and their activities responsibly and effectively

- Collect, analyse, organise and critically evaluate information

- Communicate effectively using visual, symbolic and/or language skills in various modes

- Use science and technology effectively and critically, showing responsibility towards the environment and the health of others

- Demonstrate an understanding of the world as a set of related systems by recognising that problem solving contexts do not exist in isolation (South Africa. Department of Education 2002g: II)

It is clear from these outcomes that they include all the elements of information literacy envisaged in the "Core Teaching Programme for Information Skills" of 1994. In that document, these were the skills that underlay a learners' ability to

- Define the goal of an information task

- Find sources of information

- Select appropriate resources

- Interpret the sources

- Use the information to communicate the results.(Moll 1999:2)

SA JnI Libs \& Info Sci 2009, 75(I) 


\section{Learning area outcomes}

So it is the individual Learning Area outcomes that we need to look at to see where learners are expected to show these abilities. In particular, we need to look for the presence of the following critical learning outcomes (with the key elements for information literacy in bold):

- Identify and solve problems and make decisions using critical and creative thinking

- Collect, analyse, organise and critically evaluate information

- Communicate effectively using visual, symbolic and/or language skills in various modes.

In the original Curriculum 2005, the subjects were described as having Specific Outcomes - this has been changed to Learning Outcomes in the RNCS. In the original Curriculum 2005, it was, on the face of it, easy to find where learners were expected to demonstrate their information literacy, as the Core Syllabus was kept as Specific Outcome 4 of the Learning Area then known as Language, Literacy and Communication, which was expressed as follows: "Learners obtain access to, process and use information from a variety of sources and in a variety of situations" (Moll 1999:2).

Further analysis of this outcome in Curriculum 2005 showed that it contained the entire syllabus as laid out in the Core Syllabus, merely expressed in other terms. However, this Specific Outcome was not repeated as such in the Revised National Curriculum Statement, as it was felt that Information Literacy was being seen as the domain of language teachers, and not as an underlying outcome of all learning. We therefore need to look at all the learning area outcomes in order to see where the elements shown above in the critical outcomes now appear.

\section{I Languages}

The Learning Outcomes of Language are:

- Listening

- Speaking

- Reading and Viewing

- Writing

- Thinking and Reasoning

- Language Structure and use (South Africa. Department of Education 2002c:7).

Key to Information Literacy are the Outcomes $3-5$. These are expanded as follows (bold indicating links to Information Literacy).

- Outcome 3: Reading and Viewing. The learner will be able to read and view for information and enjoyment, and respond critically to the aesthetic, cultural and emotional values in texts.

- Outcome 4: Writing. The learner will be able to write different kinds of factual and imaginative texts for a wide range of purposes.

- Outcome 5: Thinking and Reasoning. The learner will be able to use language to think and reason, as well as to access, process and use information (South Africa. Department of Education 2002c: II-14).

\subsection{Mathematics}

The Learning Outcomes for Mathematics are

- Numbers, Operations and Relationships

- Patterns, Functions and Algebra

- Space and shape (Geometry)

- Measurement

- Data handling (South Africa. Department of Education 2002e:6)

Although within each of the outcomes opportunities are given to use information that learners are expected to source (for example, it is suggested under Outcome 3 to "use national flags to demonstrate transformation and symmetry in design") (South Africa. Department of Education 2002e:10), it is Outcome 5 that is most important. Expanded it as follows (again with bold indicating Information Literacy linkages): Learning Outcome 5: Data handling. The learner will be able to collect, summarise, display and critically analyse data in order to draw conclusions and make predictions, and to interpret and determine chance variation. (South Africa. Department of Education 2002e: I2).

\subsection{Natural Sciences}

The Learning Outcomes for Natural Sciences are:

- Scientific investigations

- Constructing Science knowledge

- Science, society and the environment (South Africa. Department of Education 2002f:6).

The curriculum designers themselves noted the linkages of these outcomes to the critical outcome on information use as follows: Learning Outcome 2 was seen as most clearly representing it, but during the pursuit of Learning Outcome I, learners will build on it. These two Learning Outcomes in more detail (again with bold emphasis) are as follows: Learning 
Outcome I: Scientific Investigation. The learner will be able to act confidently on curiosity about natural phenomena, and to investigate relationships and solve problems in scientific, technological and environmental contexts.

Learning Outcome 2: Constructing Science Knowledge. The learner will know and be able to interpret and apply scientific, technological and environmental knowledge. The learners' competence in this Learning Outcome can be seen in the ability to collect or extract information from various sources and then to organise and analyse that information. (South Africa. Department of Education 2002f:9)

\subsection{Technology}

The Learning Outcomes for Technology are

- Technological Processes and skills

- Technological knowledge and understanding

- Technology, society and the environment (South Africa. Department of Education 2002i:6-9)

In some regards Technology has the closest links to Information Skills, as it employs a design process which has the skills: "investigate, design, make, evaluate, communicate" (South Africa. Department of Education 2002i:6) This is seen as part of Learning Outcome I: Technological processes and skills, which is expanded as: The learner will be able to apply technological processes and skills ethically and responsibly using appropriate information and communication technologies. The links to information literacy are made clearer in the discussion on this Outcome where the following is said (again with bold emphasis):

One of the features of a rapidly changing world is the accumulation of vast amounts of information and data. This has an impact on all aspects of modern life. Learners need to be equipped with knowledge and skills to be competent and confident in accessing and working with various forms of information and data.

These skills are included in Learning Outcome $I$ as assessment Standards related to investigating (e.g. information gathering, storing, processing, management) and communication skills (e.g. presenting information, identifying sources) (South Africa. Department of Education 2002i:7).

\subsection{Social Sciences}

The Social Sciences Learning Area is actually divided into two sections, each with its own Learning Outcomes. For History they are:

- Historical enquiry

- Historical knowledge and understanding

- Historical interpretation

For Geography

- Geographical enquiry

- Geographical knowledge and understanding

- Exploring issues (South Africa. Department of Education 2002h:7)

In both cases the first Learning Outcome is closely linked to Information Literacy and is expanded as follows (again with bold emphasis), the only difference being in the use of history or geography depending on the section. Learning Outcome I: Historical/Geographical enquiry. The learner will be able to use enquiry skills to investigate the past and the present/geographical and environmental concepts and processes. (South Africa. Department of Education 2002h:7)

This in turn is expanded as (History first and then Geography where they differ).

Important enquiry processes for this Learning Outcome include:

- Finding sources/finding sources relevant to the enquiry;

- Working with sources - asking questions, finding information, and organising, analysing and synthesising information;

- Writing a piece of history (answering a question)/answering questions and considering practical actions where possible; and

- Communicating historical knowledge and understanding (communicating an answer)/reporting on the findings of the enquiry process using different communication skills (South Africa. Department of Education 2002h:9,22)

\subsection{Arts and culture}

Arts and culture has four Learning Outcomes:

- Creating, interpreting and presenting

- Reflecting

- Participating and collaborating

- Expressing and communicating (South Africa. Department of Education 2002a: 10)

SA JnI Libs \& Info Sci 2009, 75(I) 
As with the Natural Sciences, Arts and Culture sees the Learning Area statement linking to the critical and developmental outcomes and, in particular, for Critical Outcome 4, through requiring (with bold emphasis)

- The appropriate selection of materials and the arrangement of different elements into meaningful wholes

- The collecting and organising of information about artists, art history, art careers, heritage and cultural practices (South Africa. Department of Education 2002a: 5)

This is also seen particularly in Learning Outcome 2: Reflecting (again with bold emphasis)

- The learner will be able to reflect critically and creatively on artistic and cultural processes, products and styles in past and present contexts. The learner must acquire knowledge and understanding of history of the Arts, concepts, aesthetics, culture and heritage (South Africa. Department of Education 2002a: 10).

\subsection{Life Orientation}

Life Orientation has five Learning Outcomes, of which Learning Outcome 5 is applicable only in the Senior Phase (Grades $7-9)$ :

- Health promotion

- Social development

- Personal development

- Physical development and movement

- Orientation to the world of work (South Africa. Department of Education. 2002d:9)

Links to the skills required for information Literacy can be found in Learning Outcome I: Health Promotion. In the Foundation Phase, the learner is expected to have knowledge about health matters (South Africa. Department of Education 2002d:9), but by the Intermediate Phase to use "investigative skills" (South Africa. Department of Education 2002d:25)

In addition the Assessment Standards for Learning Outcomes 5 include:

- Investigates career and study opportunities related to own interests and abilities (grade 8)

- Researches study and career funding providers (Grade 9) (South Africa. Department of Education. 2002d:49).

\subsection{Economic and Management Sciences}

There are four Learning Outcomes:

- The economic cycle

- Sustainable growth and development

- Managerial, consumer and financial knowledge and skills

- Entrepreneurial knowledge and skills. (South Africa. Department of Education 2002b:5-6)

Again, the Foundation Phase is limited - this time to only the first two Learning Outcomes. (South Africa. Department of Education 2002b:6). As with Life Orientation, the links to Information Literacy are best found in the Assessment Standards for each Learning Outcome. For learning Outcome 2, this includes

- In Grade 6: "Researches and analyses standards of living and patterns of consumption ..."(South Africa. Department of Education 2002b:25)

- In Grade 7:"Collects information on the influence ..."

- In Grade 8 "Investigates and describes how the national budget is used ..."; "Investigates how the RDP could have been used ..."; "Investigates and reports on how technology can improve productivity..."

- In Grade 9:"Investigates and debates ..." (South Africa. Department of Education 2002b:38-39)

\section{Education student intervention}

Initial teacher training at the Cape Peninsula University of Technology takes place at three campuses, each with its specific emphasis. The Bellville campus trains teachers for High Schools, specialising in Science and Technology teaching; the Mowbray and Wellington campuses train teachers for the three phases of the GET, divided into training for Foundation Phase, and training for Intermediate and Senior Phases, as well as teachers for High School, with emphasis on Mathematics and Economics education. The Mowbray campus delivers its training through the medium of English with the Wellington campus using Afrikaans.

During the first part of this year, six students from the B Ed 4 Intermediate and Senior Phase worked with the author on looking at how Information Literacy, as found in the different Learning Areas Learning Outcomes, should be incorporated into the lesson planning of the different subjects. An iterative process was followed. Students were first made aware of the potentialities, and then each planned and taught a lesson using the Information Literacy process as a teaching strategy to link the Learning Outcomes and Critical Outcome 4 to the content of the lesson. After this lesson, individual discussions were held as to lessons learned; then students planned and taught a second lesson on the same principles, but to a different level, in a different school and, therefore, with different learners. Again, there was individual 
discussion after this, and then the students were required to reflect on what they had learned, and on the implications for their own teaching.

\section{Implications for schools and school libraries}

Taking the actual input into the curriculum of Information Literacy and its associated skills on one hand, and the lessons learnt from the students on the other, the following can be seen as some of the main implications for schools and school libraries:

- The use of Information Literacy and its associated skills in the school should be an integral part of the teaching of the school. As this is seen as a cross-curricular outcome (Critical outcome 4), it is present in all learning areas

- The school therefore needs to decide on a uniform model of information Literacy training. If this is not done, either each teacher will approach the training in their own way or, as is more likely given the legacy of teachers where they have seen Information Literacy as being taught by an outside agency, namely the library, they will assume that learners are capable (thus the queue of parents at public libraries!)

- School libraries need to assert their pivotal curricular role in each learning Area. As shown above, Information Literacy is present, but often targeted to specific options, or content. The school library needs to be proactive in collaborating with the teacher to be the preferred content provider.

- Finally, there needs to be a shift in emphasis in initial teacher training - and possibly also an in-service reskilling of teachers to enable Information Literacy to take its rightful place.

\section{Conclusion}

Information Literacy is often seen as something separate from academic offerings at universities or from the Learning Areas in schools. Yet an analysis of the relevant curriculum documents underlines the importance that is placed on Information Literacy, Information Literacy Skills and even the Information Literacy Process in each of the Learning Areas that make up the curriculum in our schools. Research has shown that this needs to be taught to teachers to equip them for the task of teaching using the Information Literacy Skills and the Information Literacy Process in order to produce the learners envisaged by the authors of the curriculum:

A lifelong learner who is confident and independent, literate, numerate and multi-skilled ... with ... the ability to participate in society as a critical and active citizen. (South Africa. Department of Education 2002g: 8)

\section{References}

Arnold, Anna-Marie. 2002. National information policies - a comparative study with particular reference to South Africa and School libraries. In Singh, D, Abdullah, A, Fonseka S \& de Rosario, B. School libraries for a knowledge society: proceedings of the $3 I^{\text {st }}$ Annual conference of the international Association of School Librarianship and the Sixth International Forum on research in School Librarianship. Petaling Jaya, Malaysia, 5-9 August 2002, pp 169- 179

Moll, M.E. 1999. Kurrikulum 2005 en die Skoolbiblioteek. Die Koker 7(2): I-I2.

South Africa. Department of Education. 2002a. Revised National Curriculum Statement Grades R-9 (Schools): Arts and Culture. Pretoria: Department of Education.

South Africa. Department of Education. 2002b. Revised National Curriculum Statement Grades R-9 (Schools): Economic and Management Sciences. Pretoria: Department of Education.

South Africa. Department of Education. 2002c. Revised National Curriculum Statement Grades R-9 (Schools): Languages: English Home Language. Pretoria: Department of Education.

South Africa. Department of Education. 2002d. Revised National Curriculum Statement Grades R-9 (Schools): Life Orientation. Pretoria: Department of Education.

South Africa. Department of Education. 2002e. Revised National Curriculum Statement Grades R-9 (Schools): Mathematics. Pretoria: Department of Education.

South Africa. Department of Education. 2002f. Revised National Curriculum Statement Grades R-9 (Schools): Natural Sciences. Pretoria: Department of Education.

South Africa. Department of Education. 2002g. Revised National Curriculum Statement Grades R-9 (Schools): Overview: English. Pretoria: Department of Education.

South Africa. Department of Education. 2002h. Revised National Curriculum Statement Grades R-9 (Schools): Social Sciences. Pretoria: Department of Education.

South Africa. Department of Education. 2002i. Revised National Curriculum Statement Grades R-9 (Schools): Technology. Pretoria: Department of Education.

SA Jnl Libs \& Info Sci 2009, 75(I) 